\title{
Exploration of Innovative Education Mode Based on the 5C Concept of Core Literacy Take Bridging Education between High School and University as an Example
}

\author{
Weihe Sun* \\ Shandong Jianzhu University, Jinan, Shandong 250101, China.
}

\begin{abstract}
In recent years, with the further promotion of the concept of quality-oriented education, universities and middle schools have set up a system to further implement the high-quality humanistic quality work proposed by General Secretary Xi Jinping, comprehensively promote the process of education modernization, continuously improve the quality of personnel training, and provide high-quality and high moral talents for the society. Based on the first perspective of college students, this paper explores the implementation mode of innovative education in the bridging stage between high school and university.

Keywords: Core Accomplishment; Cohesion Phase; Innovative Education; Educational Model
\end{abstract}

\section{Introduction}

Innovativeeducation is to train people's innovative spirit and ability as the basic value orientation of education. In order to meet the challenge of the era of knowledge economy, its core is to study and solve the problem of how to cultivate students' innovative consciousness, innovative spirit and innovative ability in the field of basic education on the basis of popularizing nineyear compulsory education and in the process of comprehensively implementing quality education. Innovative education has been explored and practiced in primary and secondary schools, and how to bridge the gap between high school and university is the core content of this essay.

\section{The development background and actual situation of core accomplishment}

On March 28, 2018, China Education Innovation Research Institute of Beijing Normal University held a press conference in Beijing Normal University Beijing Normal school, and for the first time released the Research Report on the 5C Model of Core Literacy in the 21st Century (Chinese Version) and the Quality Assessment Report of China's Excellent Educational Innovation Achievements. How to train future-oriented citizens so that they are better equipped to work and live in the 21 st century. In the past ten years, the education and evaluation of core literacy in the 21 st century has increasingly attracted global attention, and even become the basis for many countries or regions to formulate education policies and carry out education reforms. ${ }^{[1]} \mathrm{The} 5 \mathrm{C}$ model includes five aspects, including Culture Competency, Critical Thinking, Creativity, Communication and Collaboration. The first letter of these five qualities is $\mathrm{C}$, so this model is called the $5 \mathrm{C}$ model of core literacy, and these qualities are referred to as $5 \mathrm{C}$ literacy for short. ${ }^{[1]}$

As early as many years ago, China put forward the concept of quality-oriented education. In today's primary and secondary education, the concept of quality-oriented education is being gradually implemented and deepened. Not only primary and secondary schools began to popularize quality education related courses, in the university stage is to put the cultivation of literacy into practice. However, during the transition period between high school and university, there are changes in teaching models and

Copyright (C) 2020 Weihe Sun

doi: 10.18282/1-e.v9i4.1729

This is an open-access article distributed under the terms of the Creative Commons Attribution Non-Commercial License (http://creativecommons.org/licenses/by-nc/4.0/), which permits unrestricted non-commercial use, distribution, and reproduction in any medium, provided the original work is properly cited.

\section{References}

[1]. USA Internet Network Information Center, 2019

[2]. Robert K.Yin. Case Study Research and application, Design and Methods[M]. sixth Edition, Sage Publications, Beverly Hills,2000.

[3].Garvin,D.A, Building a Learning Organization[M].Harvard Business, 1993.

[4]. Lister, Martin, Dovey, Jon, Giddings, Seth. Grant, Iain. \& Kelly, Kieran . New Media: A Critical Introduction[M]. London, Routledge, 2018 . 
educational concepts. As a gap period, the 5C concepts of core literacy and innovative education still need to be deepened.

\section{Four perspectives of innovative education in the linkage stage of colleges and universities}

\subsection{The perspective of cultural understanding and inheritance.}

Cultural understanding and inheritance play a guiding role in all behaviors. More and more experts and scholars began to emphasize that cultural understanding and inheritance is the core of the core literacy in the 21 st century. Cultural understanding and inheritance literacy refers to the process and behavior of people's cognition and understanding of culture, inheritance and Suckling, development and innovation, which has far-reaching significance for individual development and social harmony. For the harmonious development of the whole society, the value orientation and code of conduct contained in cultural understanding and inheritance are the cornerstone of cohesion of people's minds, which can promote individuals in social groups to work together and build a spiritual home together. Understanding and inheriting the excellent Chinese culture is a core content of cultural understanding and inheriting accomplishment.

The combination of innovative education and cultural understanding and inheritance is mainly reflected in the cultural innovation based on the excellent traditional Chinese culture. The differences in education modes between high schools and universities make students need to adapt to practice and innovation orientation. In many innovation and entrepreneurship competitions of colleges and universities, they adhere to the core guidance of culture. The understanding and inheritance of culture is not only the fundamental ideological guidance of innovative education, but also the clue that runs through the whole process of innovative education.

\subsection{The perspective of critical thinking.}

Critical thinking is a kind of reflective thinking, which emphasizes the process of explaining, analyzing, evaluating, reasoning, demonstrating, self-regulating and making judgments and decisions through careful thinking and using previous knowledge and various evidences. The process of cultivating the critical thinking of talents in higher education is also the process of training the ability of analyzing problems. ${ }^{[1]}$ In our society, each individual has a different role to play, especially in the transition stage from high school to university, which is relatively short but requires students to complete the transformation of identity and thinking mode. Unlike high school, where the learning content is relatively fixed, college students are guided to change their thinking and get out of the fixed thinking mode, and inspire innovative education through field exploration, scientific research, group discussion and other modes during the university stage with more abundant extracurricular activities and practical content. ${ }^{[2]}$

\subsection{The perspective of innovation.}

E. P. Torrance believes that creativity is a process, which first needs to be sensitive to problems, defects and disharmonious factors, and then find out the crux of the problem, and in the process of seeking solutions, make conjectures or hypotheses, and correct the hypotheses through experiments, and finally publish the results. He borrows Guilford's theory of divergent thinking and divides creative thinking into four categories: fluency, flexibility, originality and refinement. Emphasize the process of innovation, pay attention to students' explicit behavioral input, rather than simply pursue the results of creative products. Therefore, the author suggests that when cultivating students' innovation literacy, we should not pay too much attention to the results, but should pay attention to encouraging students' behavioral investment in creative activities, and emphasize "whether to do or not to do". ${ }^{[3]}$ In this way, it is necessary to create task situations conducive to the expression and output of innovation literacy, design learning tasks that are connected with the core content, problems come from real situations, increase the integration of disciplines, and emphasize the progressive thinking of students.

\subsection{The communication and cooperation perspective.}

Communication and teamwork focus on reflecting individual social skills. Communication emphasizes respect, understanding and empathy, while cooperation emphasizes the necessary persistence and compromise under the premise of achieving common goals. Effective communication and collaboration can help achieve higher quality innovation. Compared with high schools, higher education institutions have higher requirements for communication and cooperation, which are not only the necessary conditions for interpersonal communication, but also the prerequisite elements for completing group tasks and achieving more remarkable results. ${ }^{[4]}$ In institutions of higher learning in the process of innovation education, team cooperation, and practice exploration activities can effectively inspire the students' collective consciousness and communication ability, innovation education cannot do without communication, communication is one of the conditions of the cause of every innovation, communication, also can be understood as the process of the thinking process of collision, the two complement each other, promote each other relations.

\section{References}

[1]Research Report on 5 C Model of Core Literacy in the 21st Century (Chinese Version)

[2]Zang Xiaojia, car forward, Yin Xiaohuang. Cross-disciplinary thinking and cross-cultural qualities: a reference to American experience in undergraduate education [J].].1 Journal of Nanjing Normal University (Social Sciences Edition),2021(01):139-146. [3] Sun Xin, Yang Yang, Chen Lei, Huang Bo. An Analysis of the Connotation of General Education in the New Era and the Practice Mode of Colleges and Universities with Industry Characteristics [J].]; and Science and Technology Entrepreneurship monthly ,2020,33(12):135-139.

[4] Jiang Xinghong. A Study on the Cultivation and Promotion of College Students' Quality in the Reform of Innovation and Entrepreneurship Education [J]. Research and practice of innovative Entrepreneurship Theory ,2020,3(24):81-83. 